\title{
Effects of Yttrium Addition on the Microstructure Evolution and Electrochemical Corrosion of SN-9Zn Lead-Free Solders Alloy
}

\author{
Wenchao Yang ${ }^{1,2} \mathbb{D}^{1}$, Jun Mao ${ }^{1,2}$, Yueyuan Ma ${ }^{1,2}$, Shuyuan $\mathrm{Yu}^{3, *}$, Hongping He ${ }^{4}$, Da Qi ${ }^{1,2}$ and \\ Yongzhong Zhan 1,2,* \\ 1 College of Materials Science and Engineering, Guangxi University, Nanning 530004, China; \\ ywch053@163.com (W.Y.); 1815301030@st.gxu.edu.cn (J.M.); fishcat7@hotmail.com (Y.M.); \\ qdksyjs2020@163.com (D.Q.) \\ 2 Guangxi Key Laboratory of Processing for Non-Ferrous Metals and Featured Materials, \\ MOE Key Laboratory of New Processing Technology for Non-Ferrous Metals and Materials, \\ Nanning 530004, China \\ 3 Shenzhen Customs Industrial Products Inspection Technology Center, Shenzhen 518067, China \\ 4 College of Chemistry and Environmental Engineering, Shenzhen University, Shenzhen 518060, China; \\ hehp@szu.edu.cn \\ * Correspondence: szciqysy@126.com (S.Y.); zyzmatres@163.com (Y.Z.)
}

check for

updates

Citation: Yang, W.; Mao, J.; Ma, Y.; Yu, S.; He, H.; Qi, D.; Zhan, Y. Effects of Yttrium Addition on the

Microstructure Evolution and Electrochemical Corrosion of SN-9Zn Lead-Free Solders Alloy. Materials 2021, 14, 2549. https://doi.org/ $10.3390 /$ ma14102549

Academic Editor: Albena Paskaleva

Received: 6 April 2021

Accepted: 7 May 2021

Published: 14 May 2021

Publisher's Note: MDPI stays neutral with regard to jurisdictional claims in published maps and institutional affiliations.

Copyright: (c) 2021 by the authors. Licensee MDPI, Basel, Switzerland. This article is an open access article distributed under the terms and conditions of the Creative Commons Attribution (CC BY) license (https:// creativecommons.org/licenses/by/ $4.0 /)$.

\begin{abstract}
Electrochemical corrosion behavior of ternary tin-zinc-yttrium (Sn-9Zn-xY) solder alloys were investigated in aerated $3.5 \mathrm{wt} . \% \mathrm{NaCl}$ solution using potentiodynamic polarization techniques, and the microstructure evolution was obtained by scanning electron microscope (SEM). Eight different compositions of Sn-9Zn-xY ( $x=0,0.02,0.04,0.06,0.08,0.10,0.20$, and 0.30 wt. $\%)$ were compared by melting. The experimental results show that when the content of $Y$ reached $0.06 \mathrm{wt} . \%$, the grain size of $\mathrm{Zn}$-rich phase became the smallest and the effect of grain refinement was the best, but there was no significant effect on the melting point. With the increases of $Y$ content, the spreading ratio first increased and then decreased. When the content of $\mathrm{Y}$ was $0.06 \mathrm{wt} . \%$, the Sn-9Zn-0.06Y solder alloy had the best wettability on the $\mathrm{Cu}$ substrate, which was increased by approximately $20 \%$ compared with Sn-9Zn. Besides, the electrochemical corrosion experimental shows that the $Y$ can improve the corrosion resistance of $\mathrm{Sn}-9 \mathrm{Zn}$ system in $3.5 \mathrm{wt} . \% \mathrm{NaCl}$ solution, and the corrosion resistance of the alloy is better when the amount of $\mathrm{Y}$ added is larger within $0.02-0.30 \mathrm{wt}$.\%. Overall considering all performances, the optimal performance can be obtained when the addition amount of $\mathrm{Y}$ is 0.06 .
\end{abstract}

Keywords: lead-free solder; Sn-Zn; electrochemical corrosion; microstructure evolution

\section{Introduction}

$\mathrm{Sn}-\mathrm{Pb}$ solders have been widely used as interconnecting materials in electronic products because of their good physical condition and low cost [1,2]. However, lead and its compounds have high toxicity, which is harmful to the environment and human health. Lead-free solder must be researched to replace the traditional $\mathrm{Sn}-\mathrm{Pb}$ solder. The most widely researched lead-free solder systems include Sn-Ag [3-5], Sn-Cu [6-8], Sn-Bi [9-11], and Sn-Zn [12-15] binary alloys and Sn-Ag-Cu [16,17], Sn-Zn-Al [18], Sn-Zn-Bi [19], and Sn-Zn-Ag [20] ternary alloys. The Sn-9Zn (198 $\left.{ }^{\circ} \mathrm{C}\right)$ eutectic solder has become one of the most advantageous candidates, not only because of its excellent mechanical properties and close melting point to $\mathrm{Sn}-37 \mathrm{~Pb}\left(183^{\circ} \mathrm{C}\right)$, but also its rich reserves of $\mathrm{Zn}$ elements, low production cost, and nontoxicity. However, there are still practical challenges that need to be solved in application.

As one of the most promising representatives of lead-free solder, Sn-Zn has many unparalleled performance advantages and properties. However, due to the active chemical 
nature of zinc, it easily reacts with moisture and gas in air, resulting in corrosion problems. $\mathrm{Sn}-\mathrm{Zn}$ is sensitive to chemical reactions with water and oxygen in the air, leading to corrosion and affecting practical applications. In the past few years, several researchers have studied Sn-Zn [21-23] systems, focusing on mechanical properties and wetting performance. However, there are relatively few studies on its corrosion performance. Thus, the corrosion behavior of $\mathrm{Sn}-\mathrm{Zn}$ needs to be studied further. The alloying method is an effective way to obtain the refined microstructure of solders. For example, after adding $\mathrm{Cr}$, $\mathrm{Ti}$, and Al to the Sn-Zn alloy matrix, a refined microstructure can be obtained, and the oxidation resistance can be improved [12,24-26]. The addition of Ag to Sn-Zn can form uniformly dispersed $\mathrm{Ag}_{5} \mathrm{Zn}_{8}$ and $\mathrm{AgZn} \mathrm{n}_{3}$ phase matrices, which can effectively display a coarse, $\mathrm{Zn}$ rich phase and improve the corrosion resistance of the solder [20]. Besides, introducing the Bi element into the Sn-Zn system can lower the melting point of the composite solder. However, an overdose doping of Bi will lead to the formation of a thick dendritic structure of the solder alloy and reduce the mechanical properties of the solder [19]. The rare earth (RE) elements have been considered as vitamins of metals, because a tiny amount of RE elements can significantly improve the properties of alloys. Zhang et al. [27] reported that the proper amount of $Y$ can not only refine the structure of the $S n-Z n$ alloy but also improve the wettability and mechanical properties of the $\mathrm{Sn}-\mathrm{Zn} / \mathrm{Cu}$ solder joint and enhance the oxidation resistance of the solder alloy. Besides, as connecting material, the corrosion resistance of the solder plays a decisive role in the service life and safety of electronic products. Thus, in this study, the influence of $Y$ on the electrochemical corrosion performance and microstructure evolution of Sn-9Zn-xY were investigated.

\section{Experimental Procedures}

\subsection{Material Fabrication}

Sn-9Zn-xY composite solders were prepared by melting pure metals with a purity higher than $99.99 \%$. The chemical composition table of solder alloy is shown in Table 1. First, the intermediate alloy $\mathrm{Sn}-1.5 \mathrm{Y}$ was prepared in a vacuum arc furnace (WK-II, Physcience Opto-electronics Co., Ltd., Beijing, China) under an argon (Ar) atmosphere. Then, the intermediate alloy Sn-1.5Y, tin (Sn), and zinc ( $\mathrm{Zn}$ ) were weighed in accordance with the ratio and melted in a programmable heating furnace (SX2-10-12). The alloy was insulated at $350{ }^{\circ} \mathrm{C}$ for $1 \mathrm{~h}$, and the surface was mantled with $\mathrm{KCl}-\mathrm{LiCl}$ molten salt to prevent evaporation and oxidation. The melted alloy was poured into the mold and cooled naturally in the air to produce a composite solder alloy. The experiment mainly used X-ray Powder diffractometer (XRD), scanning electron microscope (SEM), Differential Scanning Calorimeter (DSC), the potentiodynamic polarization method, and cathode and anode extrapolation to study the properties of the alloy.

Table 1. Chemical compositions of the Sn-9Zn-XY alloy (wt.\%).

\begin{tabular}{cccc}
\hline Solder Alloy & Sn (wt.\%) & Zn (wt.\%) & Y (wt.\%) \\
\hline Sn9Zn & 91.00 & 9 & 0 \\
Sn9Zn0.02Y & 90.98 & 9 & 0.02 \\
Sn9Zn0.04Y & 90.96 & 9 & 0.04 \\
Sn9Zn0.06Y & 90.94 & 9 & 0.06 \\
Sn9Zn0.08Y & 90.92 & 9 & 0.08 \\
Sn9Zn0.10Y & 90.90 & 9 & 0.1 \\
Sn9Zn0.20Y & 90.80 & 9 & 0.2 \\
Sn9Zn0.30Y & 90.70 & 9 & 0.3 \\
\hline
\end{tabular}

\subsection{Microstructural Observation}

The prepared sample was subjected to phase analysis. Using a Rigaku D/Max2500V X-ray diffractometer (Rigaku Corporation, Tokyo, Japan), the working voltage was $40 \mathrm{kV}$, the current was $100 \mathrm{~mA}$, and the scanning angle was $20-80^{\circ}$ at a rate of $8^{\circ} / \mathrm{min}$. 
The sample was embedded in epoxy resin, roughed by sandpaper 600 \#-5000 \#, and polished with $0.5 \mu \mathrm{m}$ diamond paste. Then, the morphology of the sample was observed by SEM (Hitachi S-3400N, HITACHI, Tokyo, Japan).

\subsection{Wettability Measurements}

In the wettability experiment, we chose to use the copper substrate, which is a square copper sheet with a size of $40 \mathrm{~mm} \times 40 \mathrm{~mm} \times 2 \mathrm{~mm}$. Above all, we needed to preprocess the copper substrate. First, it was polished with 1000 \# water sandpaper. Then, ultrasonic cleaning was performed in acetone to remove oil stains. The copper substrate was rinsed with deionized water and dried. After rinsing with deionized water, the substrate was soaked in $10 \% \mathrm{HCl}$ solution for $10 \mathrm{~s}$ to remove the surface oxide, rinsed thoroughly with deionized water, and blow-dried. Then the solder ball was placed in the center of the copper substrate, and the substrate was placed on an alumina oxide boat. After dropping the flux, the alumina oxide boat was smoothly placed into the resistance furnace for $250{ }^{\circ} \mathrm{C}$, where it remained for $120 \mathrm{~s}$. After taking it out, it was left to cool to room temperature and rinsed with water. According to the shape of the solder joint formed after the solder spreading solidification, the spreading rate $S_{R}$ was calculated by Equation (1):

$$
S_{R}=\frac{D-H}{D} \times 100 \%
$$

where $S_{R}$ is the spreading ratio, $H$ is the height of the solder after the wetting test, and $D$ is the diameter of the solder approximately as a sphere.

\subsection{Melting Point Test}

The melting points of the solder alloys were determined by DSC with the Synchronous Thermal Analyzer (Setaram Labsys Evo, SETARAM, Lyon, France). Approximately $30 \pm 10 \mathrm{mg}$ of the composite solder was placed in an alumina crucible under the protection of Ar atmosphere. The temperature of the instrument was first heated from room temperature to $150{ }^{\circ} \mathrm{C}$ at a heating rate of $10^{\circ} \mathrm{C} / \mathrm{min}$. Then, it was heated to $250{ }^{\circ} \mathrm{C}$ at a rate of $5^{\circ} \mathrm{C} / \mathrm{min}$.

\subsection{Electrochemical Measurements}

The composite solder wire was cut into a block with a cross-sectional area of $10 \mathrm{~mm} \times 10 \mathrm{~mm}$ and a thickness of about $3 \mathrm{~mm}$. The square section was polished with 3000 \# as the working face, and the other side was pasted with copper paste, welded with copper wire as the lead, and sealed with paraffin. The reference electrode used in $3.5 \mathrm{wt}$ \% $\mathrm{NaCl}$ solution was calomel electrode, and the auxiliary electrode used was platinum electrode. The CHI660D electrochemical analyzer (Shanghai Chenhua Instrument Company, Shanghai, China) was used to test the Sn-9Zn-xY sample with a scanning range of $-2000 \mathrm{mV} \sim 500 \mathrm{mV}$ and a scanning rate of $2 \mathrm{mV} / \mathrm{s}$.

\section{Results and Discussion}

\subsection{Microstructures of Sn-9Zn-xY Solder Alloys}

Figure 1 shows the XRD peaks of the Sn-9Zn-xY $(x=0,0.02,0.06,0.10,0.20$, and 0.30 wt.\%) alloys. Peaks were matched by Jade 6.0. Sn-9Zn-xY solder alloys were mainly composed of a large number of $\beta$-Sn phases and a small amount of $\mathrm{Zn}$ in a solid solution. However, after adding $\mathrm{Y}$, the XRD spectra line of the solder alloy did not observe the other feature peaks. However, this does not mean that there was no new material formation, and material formation may be challenging to detect when the phase content in the alloy is very small. Therefore, it is possible that a new phase was produced, but that its content was small and could not be detected. 


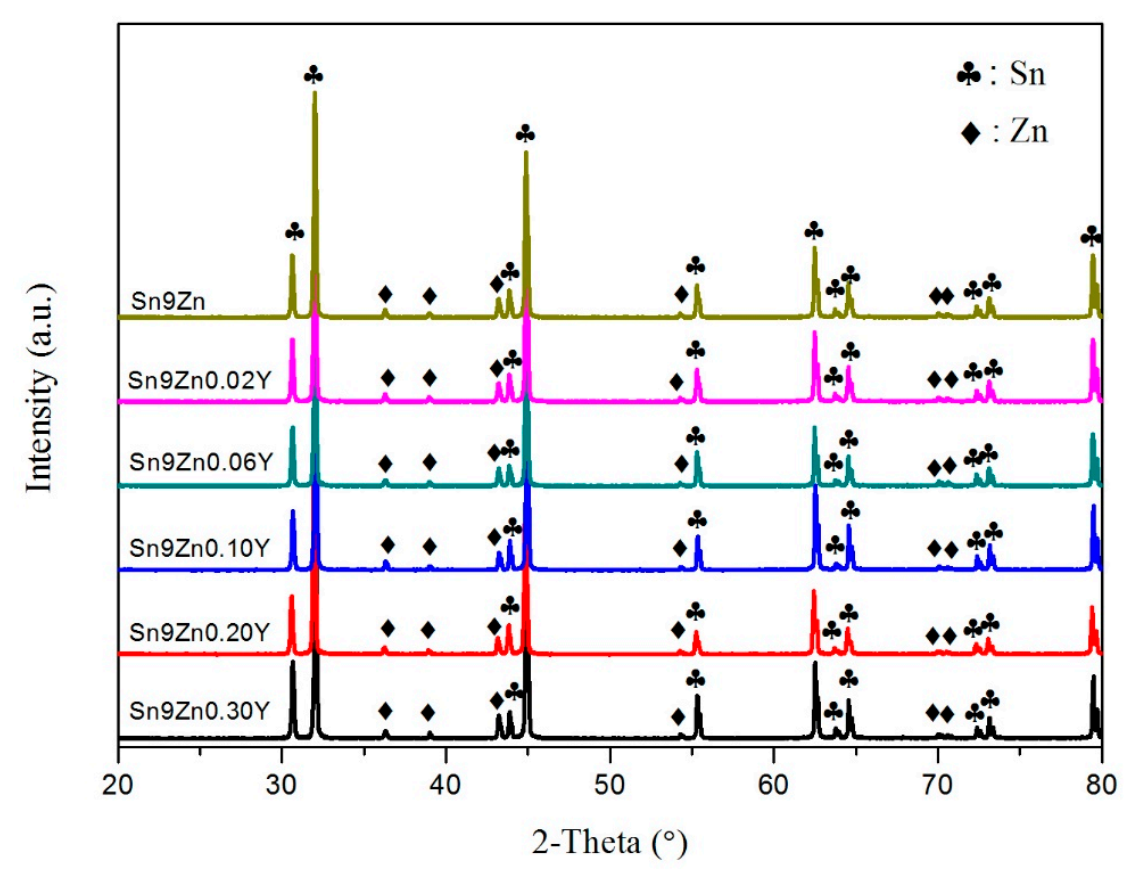

Figure 1. X-ray Powder diffractometer (XRD) diffraction pattern for Sn-9Zn-xY alloys $(x=0,0.02$, $0.06,0.10,0.20,0.30$ wt.\%).

The SEM micrographs of the Sn-9Zn-xY alloys are shown in Figure 2. Figure 2a is the representative microstructure of eutectic $\mathrm{Sn}-\mathrm{Zn}$ solder, which consists of two phases: The brighter large area is the matrix $\beta$-Sn phase, and the deeper coarse rod-like $\mathrm{Zn}$ phase is distributed on the Sn matrix. Adding $Y$ to the Sn-9Zn alloy, as shown in Figure $2 \mathrm{a}-\mathrm{h}$, led to a significant change in the shape of the Zn-rich phase from the microscopic morphology. The strip shape was smaller than the original and was uniformly distributed in the matrix $\beta$-Sn. As the $Y$ content increased, the rod-like $Z n$-rich phase was further refined. When the doping level was $0.06 \mathrm{wt}$ \% , as shown in Figure $2 \mathrm{~d}$, the Zn-rich phase in the alloy system was most uniformly distributed, and the size became finer. Compared with the Zn-rich phase in Sn-9Zn as Figure 2a, the refinement was very significant. However, as the content of $Y$ continued to increase and reached $0.2 \mathrm{wt} . \%$, as shown in Figure $2 \mathrm{~g}$, a new phase with a darkness between the Sn matrix and the Zn-rich phase appeared in the alloy, and scattered distribution was observed on the Sn matrix. This compound is $\mathrm{YSn}_{3}$. The binary Sn-Y [28] phase diagram is used to show that $\mathrm{YSn}_{3}$ is unstable at a high temperature and decomposes at $515{ }^{\circ} \mathrm{C}$. The melting point of the rare earth compound is generally high, and trace rare earth elements are present in the molten metal alloy and can be adsorbed on the surface of the grain boundary and prevent the growth of the crystal grains to achieve the effect of refining the tissue. At the same time, the rare earth compound can also reduce the surface activity point and improve the phase interface, uniformity of the surface, fluidity of the molten metal, and compactness of the microstructure. 

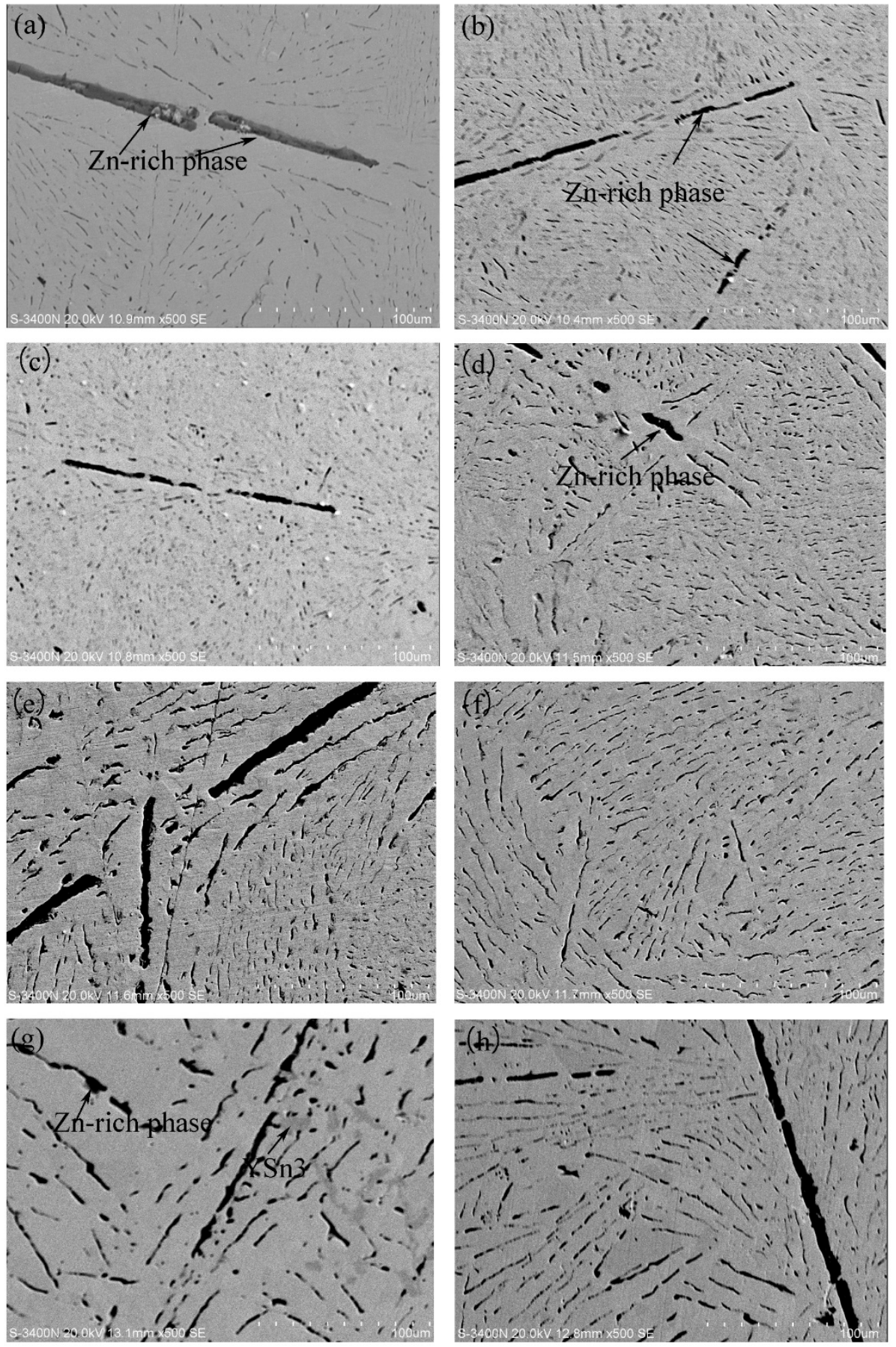

Figure 2. Scanning electron microscope (SEM) micrographs for (a) Sn-9Zn, (b) Sn-9Zn-0.02Y, (c) Sn9Zn-0.04Y, (d) Sn-9Zn-0.06Y, (e) Sn-9Zn-0.08Y, (f) Sn-9Zn-0.10Y, (g) Sn-9Zn-0.20Y, (h) Sn-9Zn-0.30Y.

\subsection{Wettability Analysis}

The spreading ratio is shown in Figure 3. As we can observe from curve, the addition of $Y$ had a significant effect on the wettability of Sn-9Zn alloy system. When $Y$ was added to the alloy, the spreading ratio of $\mathrm{Sn}-9 \mathrm{Zn}$ solder increased first and then decreased with the increase of $Y$ content. When the $Y$ content was $0.06 \mathrm{wt} . \%$, the spreading rate reached $76 \%$, and the best wettability was obtained. However, when the amount of $Y$ added continued to increase, the spreading ratio dropped sharply, and the wetting performance deteriorated. 


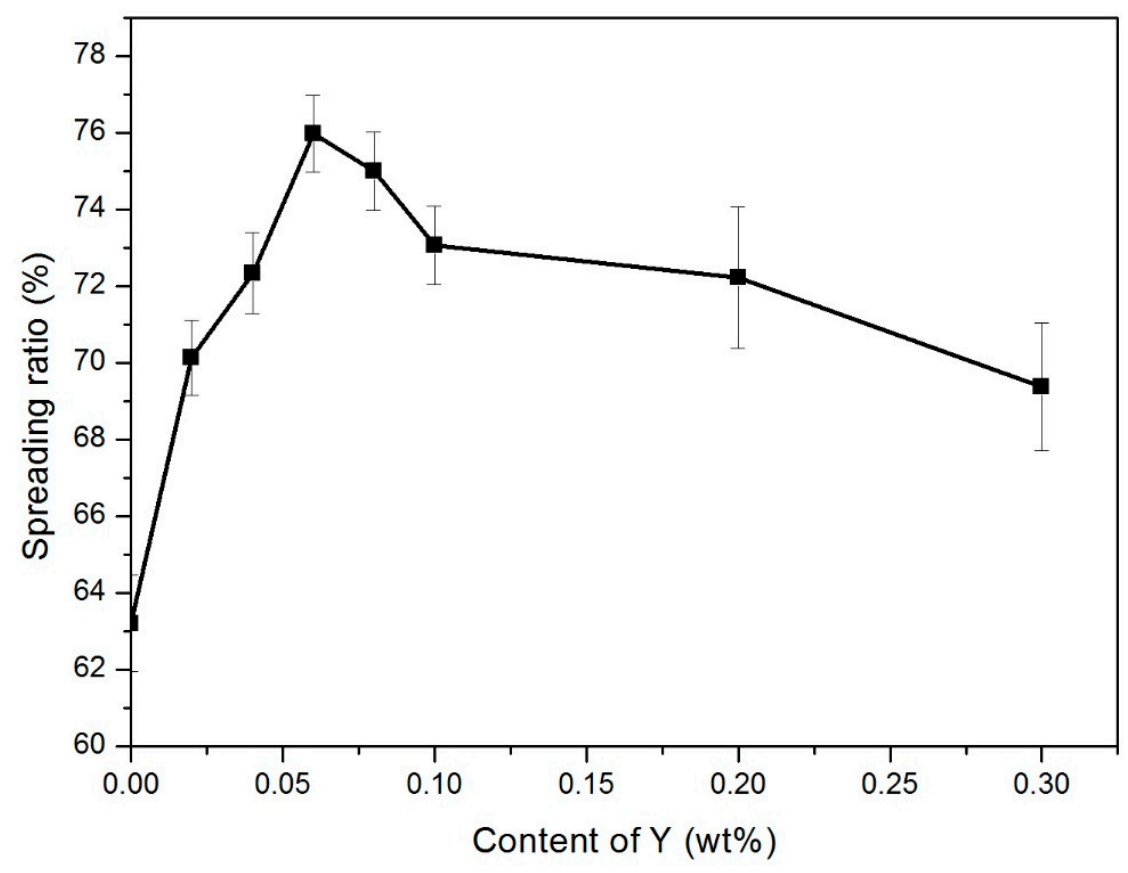

Figure 3. Spreading ratio curve of Sn-9Zn-xY alloys.

$\mathrm{Zn}$ is an active metal element in $\mathrm{Sn}-9 \mathrm{Zn}$. At $250{ }^{\circ} \mathrm{C}$, the oxidation of the $\mathrm{Zn}$ leads to the formation of oxides that are difficult to be wetted on the $\mathrm{Cu}$ substrate, resulting in poor wettability of the alloy solder. $\mathrm{Y}$ is a rare earth element, and its properties are relatively lively. Adding a trace amount can obviously affect the microstructure of the alloy. When a small amount of $Y$ is added, the original Zn-rich phase in Sn-9Zn is refined, and $\mathrm{Zn}$ is evenly distributed in the matrix so that the $\mathrm{Zn}$ in the matrix no longer polymerizes in a simple form. At high temperatures, the degree of oxidation is reduced compared to when it is not refined, so the wetting performance is increased. The refinement is most obvious when the content of $\mathrm{Y}$ is $0.06 \mathrm{wt} . \%$, so the oxidation degree of $\mathrm{Zn}$ is the smallest and the wetting performance is the best. However, when a larger amount of $Y$ is added, the active compound $\mathrm{YSn}_{3}$ in the matrix will also generate oxides that are not easy to wet with the base metal copper plate at high temperatures. Thus, the spreading rate of the solder is reduced, and the wettability of the solder alloys and the base metal copper plate is deteriorated. In summary, with the increase of $Y$ content, there is a certain refinement effect on the crystal grain, but the increase in wettability is mainly due to the surface activity of rare earth elements, which are easier to agglomerate at the solder/flux interface in the molten state, reducing the liquid solder. The interface surface tension between the material and the substrate accelerates the wetting of the brazing alloy to the copper substrate [29-31]. However, excess $Y$ can also cause a decrease in solderability, which is caused by an increase in the viscosity of the solder. When the $\mathrm{Y}$ content is too high, it easily forms oxides, but it increases the surface tension and deteriorates the wetting behavior.

\subsection{Melting Temperature}

Figure 4 shows the DSC curve of Sn-9Zn-xY solder alloys. From the overall curve, during the heating process of the metal, the alloy had an endothermic reaction near the melting point. Because the metal underwent a phase transition reaction during the melting process to absorb heat, and there was a peak of depression. As can be seen from Figure 4, the sample underwent endothermic reaction at point A, and its heat flux dropped sharply. Point A defines the starting point of alloy melting, which is the solidus temperature. As the sample temperature continued to increase, the sample underwent a eutectic melting reaction within a certain range after point $\mathrm{A}$, and the reaction endothermic heat flow showed a downward peak. Point B is the peak of the endothermic peak, and the temperature corresponding to this peak is the melting point. The melting process of most 
alloys occurs in the temperature range from point $A$ to point $C$. When the temperature rises beyond point $C$, the heat flow flattens out, the metal is completely liquefied, and the melting process ends.
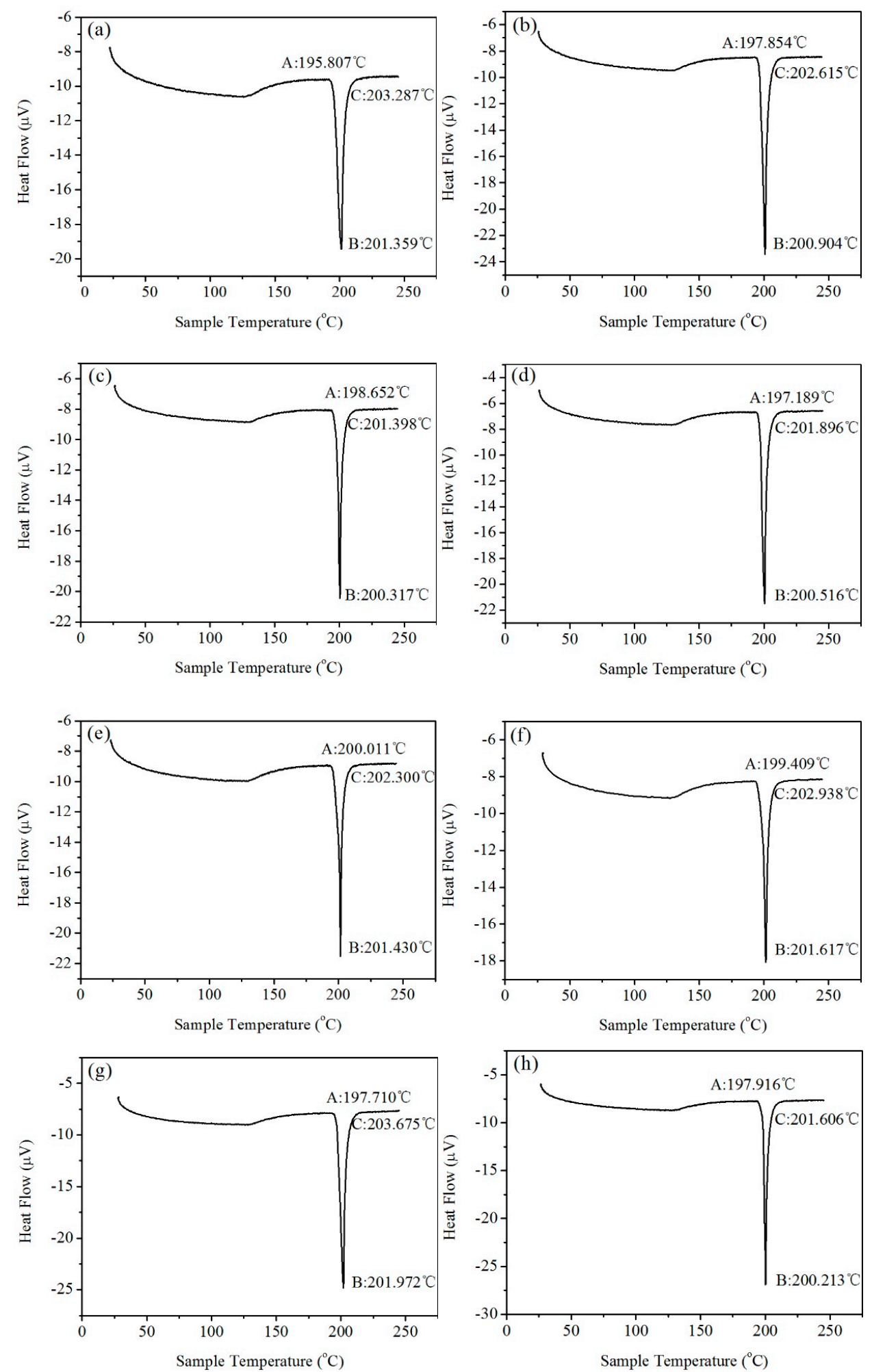

Figure 4. The Differential Scanning Calorimeter (DSC) curves of Sn-9Zn-xY alloys: (a) Sn-9Zn, (b) Sn-9Zn-0.02Y, (c) Sn-9Zn-0.04Y, (d) Sn-9Zn-0.06Y, (e) Sn-9Zn-0.08Y, (f) Sn-9Zn-0.10Y, (g) Sn-9Zn-0.20Y, (h) Sn-9Zn-0.30Y. 
The initial melting temperature, melting point, and melting range of the Sn-9Zn-xY solder alloys are listed in Table 2. The melting point and melting range curve of the Sn-9ZnxY solder alloys are shown in Figure 5. According to the analysis in Table 2 and Figure 5, the melting point of Sn-9Zn-0.30Y was the lowest, but only about $1{ }^{\circ} \mathrm{C}$ lower than that of $\mathrm{Sn}-9 \mathrm{Zn}$. Moreover, the melting process of $\mathrm{Sn}-9 \mathrm{Zn}-0.08 \mathrm{Y}$ was the lowest, but only about $3{ }^{\circ} \mathrm{C}$ lower than that of Sn-9Zn. These small changes indicate that the amount of $\mathrm{Y}$ added does not have a great influence on the melting point and melting range of the alloy. A small amount of $Y, S n$, and $\mathrm{Zn}$ do not generate high melting point compounds. In turn, the melting point of the alloy does not increase, nor is the melting point significantly reduced. When adding $\mathrm{Y}$ content to $\mathrm{Sn}-9 \mathrm{Zn}$ in the range of $0-0.3 \mathrm{wt} . \%$ to improve other properties, $\mathrm{Y}$ will not have significant influence on the melting properties of the $\mathrm{Sn}-9 \mathrm{Zn}$ solder alloys.

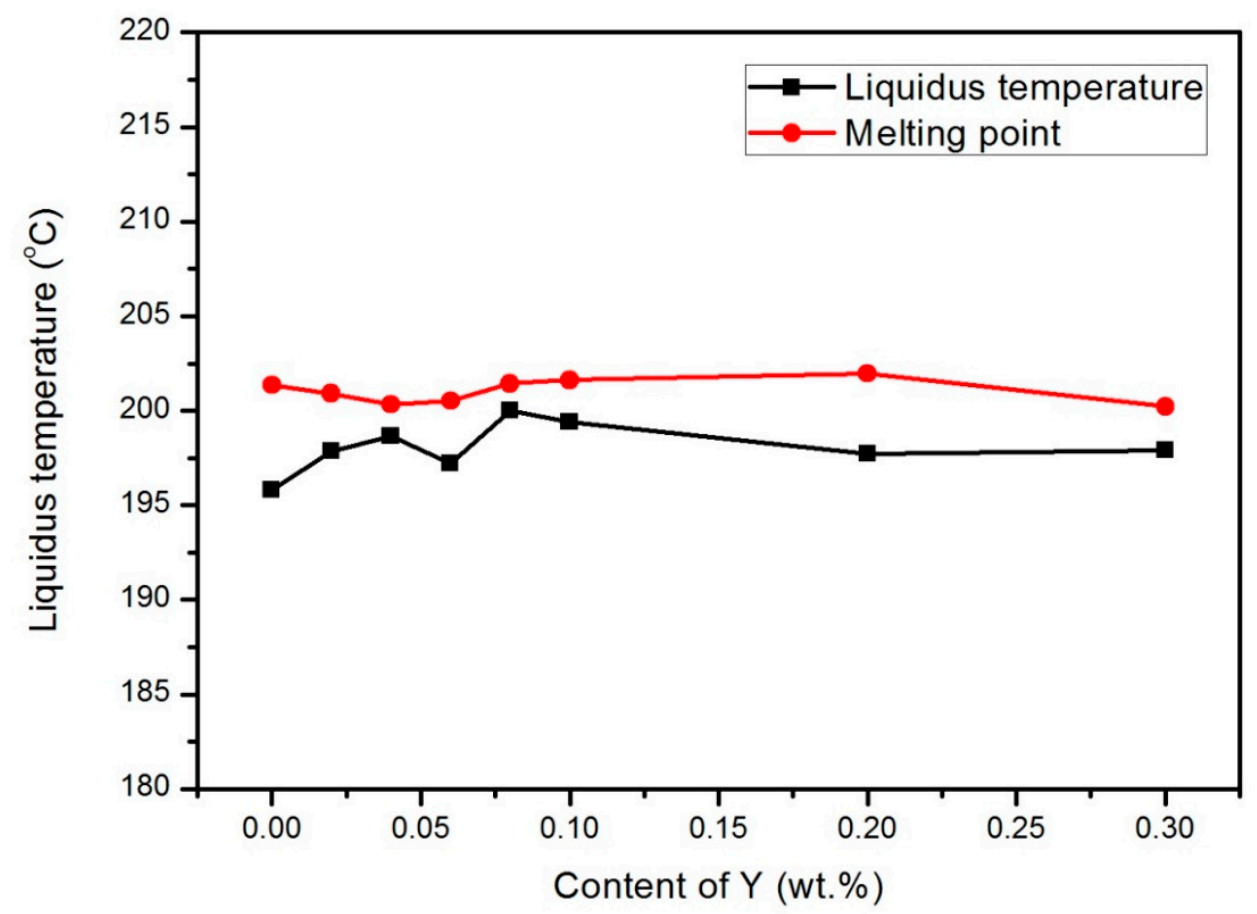

Figure 5. Melting point and melting range curves of the Sn-9Zn-xY solder alloys.

Table 2. DSC results of the Sn-9Zn-xY solder alloys.

\begin{tabular}{cccc}
\hline Solder Alloy & Solid Phase Line, ${ }^{\circ} \mathbf{C}$ & Melting Point, ${ }^{\circ} \mathbf{C}$ & Melting Range, ${ }^{\circ} \mathbf{C}$ \\
\hline Sn9Zn & 195.8 & 201.4 & 5.6 \\
Sn9Zn0.02Y & 197.8 & 200.9 & 3.1 \\
Sn9Zn0.04Y & 198.7 & 200.3 & 1.6 \\
Sn9Zn0.06Y & 197.2 & 200.5 & 3.3 \\
Sn9Zn0.08Y & 200.0 & 201.4 & 1.4 \\
Sn9Zn0.10Y & 199.4 & 201.6 & 2.2 \\
Sn9Zn0.20Y & 197.7 & 201.9 & 4.2 \\
Sn9Zn0.30Y & 197.9 & 200.2 & 2.3 \\
\hline
\end{tabular}

\subsection{Electrochemical Behavior}

The Sn-9Zn-xY solder alloys was studied by potentiodynamic polarization to determine the effect of varying $Y$ content on the corrosion resistance. Figure 6 shows the electric polarization plots of Sn-9Zn-xY ( $x=0,0.02,0.04,0.06,0.08,0.10,0.20,0.30 \mathrm{wt} . \%)$ solders in $3.5 \mathrm{wt} . \% \mathrm{NaCl}$ solution. The polarization curve in the range of $-2000 \mathrm{mV}$ to $+500 \mathrm{mV}$ at a scanning speed of $2 \mathrm{mV} / \mathrm{s}$ was investigated. 


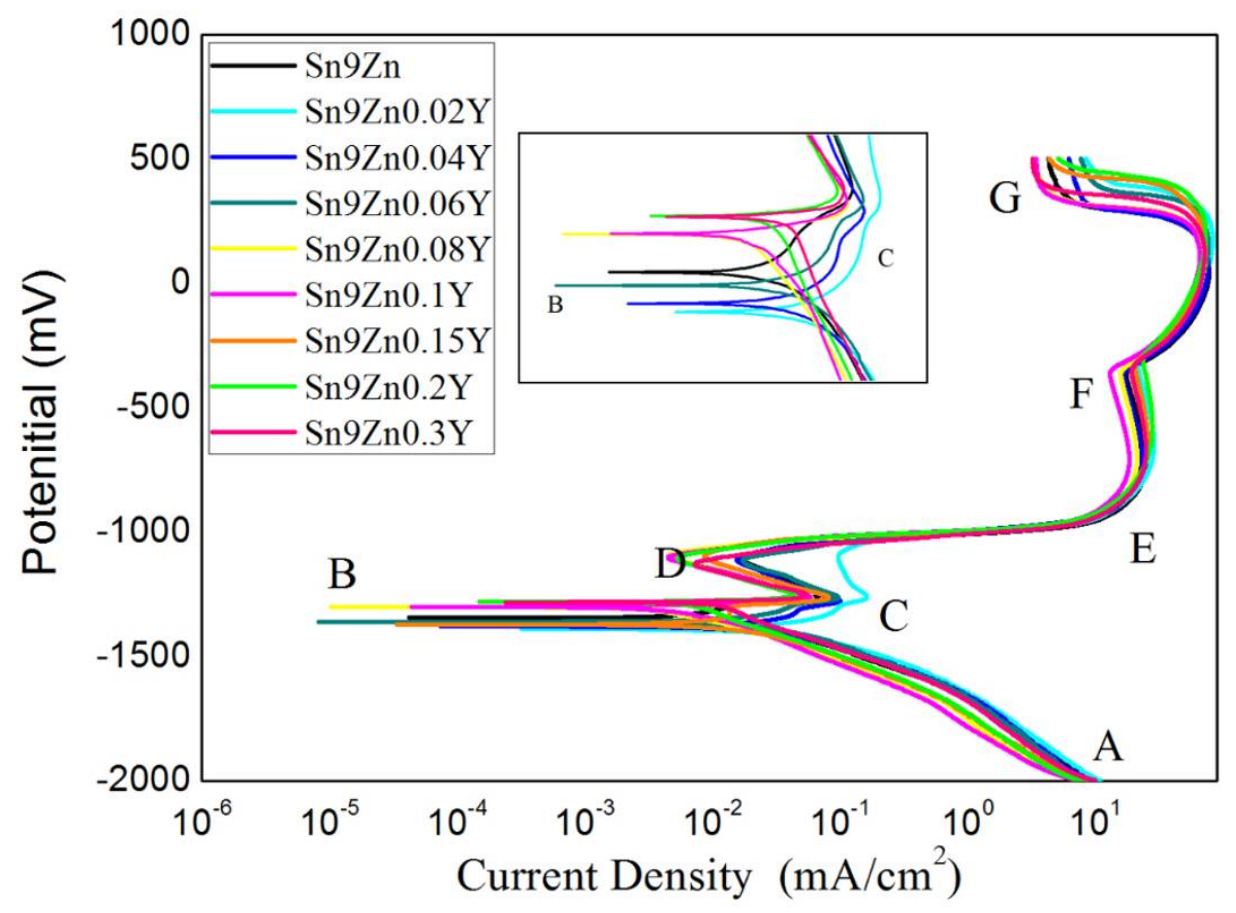

Figure 6. Potentiodynamic polarization curves of $\mathrm{Sn}-9 \mathrm{Zn}-\mathrm{xY}$ solders in $3.5 \mathrm{wt}$. $\% \mathrm{NaCl}$ solution.

In the cathode region $\mathrm{AB}$, the reaction taking place is the reduction of water, that is, the formation of hydrogen $\left(\mathrm{H}_{2}\right)$ and hydroxyl ions $\left(\mathrm{OH}^{-}\right)$. During this experiment, hydrogen bubbles were observed on the surface of the sample. The reaction is as follows:

$$
2 \mathrm{H}_{2} \mathrm{O}+2 \mathrm{e}^{-} \rightarrow \mathrm{H}_{2}+2 \mathrm{OH}^{-}
$$

At point $B$, because the activity and standard electrode potential of $\mathrm{Zn}$ were lower than Sn and Y, Zn preference occurred the dissolution reaction [32,33].

$$
\begin{gathered}
\mathrm{Zn}+2 \mathrm{OH}^{-} \rightarrow \mathrm{Zn}(\mathrm{OH})_{2}+2 \mathrm{e}^{-} \\
\mathrm{Zn}+2 \mathrm{OH}^{-} \rightarrow \mathrm{ZnO}+\mathrm{H}_{2} \mathrm{O}+2 \mathrm{e}^{-}
\end{gathered}
$$

The values of the potentials for reactions (3) and (4) approached the $E_{\text {corr }}$ values listed in Table 3.

Table 3. The electrochemical corrosion parameters of Sn-9Zn-xY solder alloys in 3.5 wt.\% $\mathrm{NaCl}$ solution.

\begin{tabular}{cccc}
\hline $\mathbf{Y}(\mathbf{w t .} \mathbf{\%})$ & $\begin{array}{c}\mathbf{I}_{\text {corr }}\left(\mathbf{m A} / \mathbf{c m}^{\mathbf{2}}\right) \times \\
\mathbf{1 0}^{-\mathbf{3}}\end{array}$ & $\mathbf{E}_{\text {corr }}(\mathbf{m V})$ & $\begin{array}{c}\text { Corrosion Rate } \\
(\mathbf{m m} / \mathbf{a})\end{array}$ \\
\hline 0 & 3.81 & -1342.6 & 0.096 \\
0.02 & 39.6 & -1387.7 & 0.996 \\
0.04 & 21.6 & -1378.3 & 0.548 \\
0.06 & 7.43 & -1355.7 & 0.188 \\
0.08 & 2.09 & -1299.7 & 0.053 \\
0.1 & 3.27 & -1299.3 & 0.083 \\
0.2 & 4.39 & -1279.3 & 0.111 \\
0.3 & 5.27 & -1280.1 & 0.133 \\
\hline
\end{tabular}

As the potential continued to increase, the active dissolution of zinc continued to point $\mathrm{C}$, where the concentration reached a critical value and an ultrafine microstructure was produced on the solder surface. It was found that the current density decreased as the 
electric potential increased during region $\mathrm{CD}$, which was created by the active dissolution of $\mathrm{Sn}$ according to the reactions below:

$$
\begin{gathered}
\mathrm{Sn}+2 \mathrm{OH}^{-} \rightarrow \mathrm{Sn}(\mathrm{OH})_{2}+2 \mathrm{e}^{-} \\
\mathrm{Sn}(\mathrm{OH})_{2} \rightarrow \mathrm{SnO}+\mathrm{H}_{2} \mathrm{O}
\end{gathered}
$$

Abayarathna et al. [34] reported that the formation of zincate membranes on regional $\mathrm{CD}$ has no protective effect, and that the formation of the membranes is a process limiting transport.

The currents sharp increases during region DE may indicate more serious corrosion and weaken of the ability to form a passive film. Passivation for the solder alloys began at point E. From point $\mathrm{E}$ to point F, the current density was nearly independent of the potential. It is generally believed that zinc passivation begins with the precipitation of zincate ions in the form of $\mathrm{Zn}(\mathrm{OH})_{2}$ or $\mathrm{ZnO}$. The deposition of $\mathrm{ZnO}$ or $\mathrm{Zn}(\mathrm{OH})_{2}$ on the surface hinders the dissolution of the active sites and passivates part of the surface.

A sharp increase in current density was observed at about $-300 \mathrm{mV}$ (point F). Due to the incorporation of $\mathrm{Cl}^{-}$ions into the oxide layer, the film began to break at point $\mathrm{F}$. The potential at F point is called the breakdown potential, which is also known as the pitting potential. Under the action of pitting, certain points on the passivated film become part of the destruction. Therefore, the anode current density increased sharply.

Table 3 shows the electrochemical parameters, including the corrosion potential ( $\left.\mathrm{E}_{\mathrm{corr}}\right)$, corrosion current density $\left(\mathrm{I}_{\mathrm{corr}}\right)$, and corrosion rate. These parameters were obtained by fitting the polarization curve with Cview software. Figure 7 shows the change trend of the influence of different contents of $\mathrm{Y}$ on the self-corrosion potential. As shown in Figure 7 and Table 2, the $\mathrm{E}_{\text {corr }}$ values decreased when the addition of $Y$ content only was $0.02 \mathrm{wt} . \%$. However, with the increase of $Y$ content, Ecorr showed a tendency toward more negative potentials. The $\mathrm{E}_{\mathrm{corr}}$ of Sn-9Zn-0.06Y was close to the $\mathrm{E}_{\mathrm{corr}}$ of Sn-9Zn. With a continued increase in $\mathrm{Y}$ content, the $\mathrm{E}_{\text {corr }}$ value increased, reaching a value higher than the $\mathrm{E}_{\mathrm{corr}}$ of Sn-9Zn. Then, value remained stable with the increase of increasing $Y$ content until the $\mathrm{Y}$ reached a certain value. However, $\mathrm{I}_{\text {corr }}$ value decreased after initially increasing and then leveled off. The greatest influence on the corrosion resistance was the active $\mathrm{Zn}$ in Sn-9Zn- $x Y$ alloys. Zn was active and easily oxidized when it existed as Zn-rich phase. $Y$ refined the rich $\mathrm{Zn}$ phase, homogenized it, and reduced the probability of $\mathrm{Zn}$ corrosion on the surface of the sample to improve the corrosion resistance of the alloy. At the same time, $\mathrm{Y}$ did not generate the active compound in the alloys. A recent report by Ralston et al. [35] showed that, when testing systems with a certain degree of passivation, the corrosion rate decreases as the grain size decreases. Osório et al. [36] also proved that the corrosion behavior of Sn-Ag solder alloy is closely related to the structure of the array. Therefore, the addition of trace Ti increased the corrosion resistance of Sn-9Zn alloy due to the structural deterioration of the alloy, that is, a large number of primary zinc-rich precipitates were eliminated, and the eutectic structure become more uniform. Liu et al. [26] reported that the addition of Ti led to zinc-rich precipitation phase refinement in the structure, which is conducive to the formation of a more protective passivation film on the surface of the modified composite solder and the enhancement of the corrosion resistance of the material. 


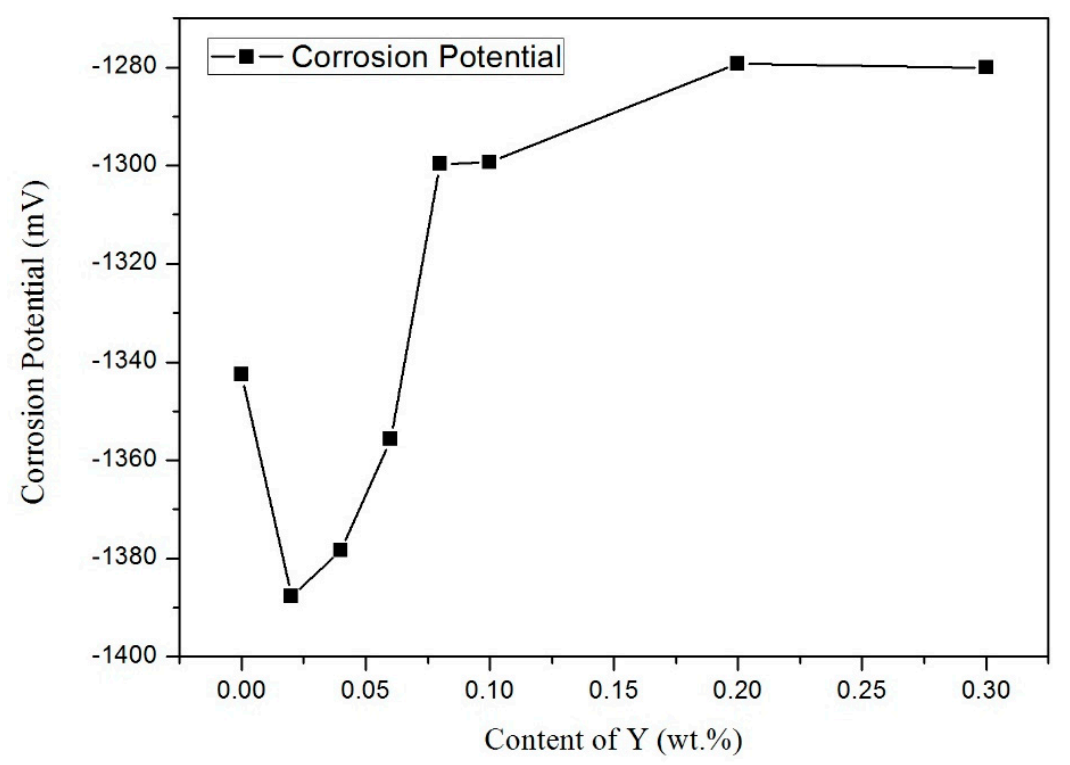

Figure 7. Effect of $\mathrm{Y}$ content on the $\mathrm{E}_{\mathrm{corr}}$ value obtained during potentiodynamic polarization of Sn-9Zn-xY in 3.5 wt.\% NaCl solution.

\section{Conclusions}

1. The addition of $Y$ refined the $Z n$-rich phase of the matrix and made the $\mathrm{Zn}$ phase narrow and uniformly distributed. When the addition of $Y$ was $0.06 \mathrm{wt} . \%$, it showed the most significant refinement effect. However, when the content of $Y$ continued to increase, $\mathrm{YSn}_{3}$ was unstable at high temperature in the matrix.

2. The spreading rate of Sn-9Zn solder increased with the addition of $Y$. When the $Y$ content was $0.06 \mathrm{wt} . \%$, the wettability was the best. However, when the amount of $Y$ added continued to increase, the wetting performance dropped sharply.

3. The amount of $Y$ added had no significant influence on the melting point and melting range of the alloy.

4. Adding $\mathrm{Y}$ to $\mathrm{Sn}-9 \mathrm{Zn}$ improved the corrosion resistance of solder. When a small amount of $Y$ was added, the corrosion resistance of the alloy was lower than that of Sn-9Zn. However, with the increase of $Y$ content, the corrosion potential increased. When Y content was $0.06 \mathrm{wt} . \%$, the corrosion potential of the alloy was close to that of the Sn-9Zn alloy. The corrosion potential increased with the increase of $Y$ content, which was higher than that of $S n-9 Z n$, and tended to a stable value. The addition of $Y$ can refine the Zn-rich phase of $\mathrm{Sn}-9 \mathrm{Zn}$ system and improve the corrosion resistance of the alloy.

Author Contributions: Conceptualization, W.Y. and Y.M.; methodology, W.Y. and Y.M.; software, J.M.; validation, J.M. and D.Q.; formal analysis, Y.Z.; investigation, W.Y. and Y.M.; resources, S.Y., H.H. and Y.Z.; data curation, J.M. and Y.M.; writing-original draft preparation, W.Y., J.M. and Y.M.; writing-review and editing, W.Y. and H.H.; visualization, Y.Z.; supervision, Y.Z.; project administration, W.Y. and Y.Z.; funding acquisition, W.Y., S.Y. and Y.Z. All authors have read and agreed to the published version of the manuscript.

Funding: This research was funded National Key R\&D Program of China, grant number 2018YFF0215502; Guangxi Natural Science Foundation grant number: 2020GXNSFBA297062, 2020GXNSFAA159093, 2018GXNSFDA050008; National Natural Science Foundation of China grant number: 51761002; Training Plan of High-Level Talents of Guangxi University grant number XMPZ160714 and Scientific research projects of the General Administration of Customs grant number: 2020HK256.

Data Availability Statement: Data is contained within the article.

Conflicts of Interest: The authors declare no conflict of interest. 


\section{References}

1. Suganuma, K. Advances in lead-free electronics soldering. Curr. Opin. Solid State Mater. Sci. 2001, 5, 55-64. [CrossRef]

2. Abtew, M.; Selvaduray, G. Lead-free solders in microelectronics. Mater. Sci. Eng. R Rep. 2000, 27, 95-141. [CrossRef]

3. Alam, M.O.; Chan, Y.C.; Tu, K.N. Effect of reaction time and P content on mechanical strength of the interface formed between eutectic Sn-Ag solder and Au/electroless Ni (P)/Cu bond pad. J. Appl. Phys. 2003, 94, 4108-4115. [CrossRef]

4. Chada, S.; Fournelle, R.A.; Laub, W.; Shuangguan, D. Copper substrate dissolution in eutectic Sn-Ag solder and its effect on microstructure. J. Electron. Mater. 2000, 29, 1214-1221. [CrossRef]

5. Gumaan, M.S.; Shalaby, R.M.; Ali, E.A.M.; Kamal, M. Copper effects in mechanical, thermal and electrical properties of rapidly solidified eutectic Sn-Ag alloy. J. Mater. Sci. Mater. Electron. 2018, 29, 8886-8894. [CrossRef]

6. Chen, W.T.; Ho, C.E.; Kao, C.R. Effect of Cu concentration on the interfacial reactions between Ni and Sn-Cu solders. J. Mater. Res. 2002, 17, 263-266. [CrossRef]

7. Tai, F.; Guo, F.; Xia, Z.D.; Lei, Y.P.; Yan, Y.F.; Liu, J.P.; Shi, Y.W. Processing and creep properties of Sn-Cu composite solders with small amounts of nanosized Ag reinforcement additions. J. Electron. Mater. 2005, 34, 1357-1362. [CrossRef]

8. Zhao, M.; Zhang, L.; Liu, Z.-Q.; Xiong, M.-Y.; Sun, L. Structure and properties of Sn-Cu lead-free solders in electronics packaging. Sci. Technol. Adv. Mater. 2019, 20, 421-444. [CrossRef]

9. Chen, Y.Y.; Duh, J.G.; Chiou, B.S. The effect of substrate surface roughness on the wettability of Sn-Bi solders. J. Mater. Sci. Mater. Electron. 2000, 11, 279-283. [CrossRef]

10. Yang, W.; Li, J.; Feng, J.; Wu, J.; Zhou, X.; Yu, A.; Wang, J.; Liang, S.; Wei, M.; Zhan, Y.; et al. Effect of Aluminum Addition on the Microstructure and Properties of Non-Eutectic Sn-20Bi Solder Alloys. Materials 2019, 12, 1194. [CrossRef]

11. Mei, Z.; Morris, J.W. Characterization of eutectic Sn-Bi solder joints. J. Electron. Mater. 1992, 21, 599-607. [CrossRef]

12. Chen, X.; Li, M.; Ren, X.X.; Hu, A.M.; Mao, D.L. Effect of small additions of alloying elements on the properties of Sn-Zn eutectic alloy. J. Electron. Mater. 2006, 35, 1734-1739. [CrossRef]

13. Suganuma, K.; Kim, K.S. Sn-Zn low temperature solder. In Lead-Free Electronic Solders; Springer: Boston, MA, USA, 2006; pp. 121-127.

14. Zhang, L.; Xue, S.-B.; Gao, L.-L.; Sheng, Z.; Ye, H.; Xiao, Z.-X.; Zeng, G.; Chen, Y.; Yu, S.-L. Development of Sn-Zn lead-free solders bearing alloying elements. J. Mater. Sci. Mater. Electron. 2010, 21, 1-15. [CrossRef]

15. Liu, M.; Yang, W.; Ma, Y.; Tang, C.; Tang, H.; Zhan, Y. The electrochemical corrosion behavior of Pb-free Sn-8.5 Zn-XCr solders in 3.5 wt.\% NaCl solution. Mater. Chem. Phys. 2015, 168, 27-34. [CrossRef]

16. Kim, K.S.; Huh, S.H.; Suganuma, K. Effects of intermetallic compounds on properties of Sn-Ag-Cu lead-free soldered joints. J. Alloys Compd. 2003, 352, 226-236. [CrossRef]

17. Xiong, M.; Zhang, L. Interface reaction and intermetallic compound growth behavior of Sn-Ag-Cu lead-free solder joints on different substrates in electronic packaging. J. Mater. Sci. 2019, 54, 1741-1768. [CrossRef]

18. Lin, K.L.; Liu, T.P. High-temperature oxidation of a Sn-Zn-Al solder. Oxid. Met. 1998, 50, 255-267. [CrossRef]

19. Zhou, J.; Sun, Y.; Xue, F. Properties of low melting point Sn-Zn-Bi solders. J. Alloys Compd. 2005, 397, 260-264. [CrossRef]

20. Song, J.M.; Lan, G.F.; Lui, T.S.; Chen, L.H. Microstructure and tensile properties of Sn-9Zn-xAg lead-free solder alloys. Scr. Mater. 2003, 48, 1047-1051. [CrossRef]

21. Wang, Y.; Peng, J.; Zhong, L. On the microstructure and mechanical property of as-extruded Mg-Sn-Zn alloy with Cu addition. J. Alloys Compd. 2018, 744, 234-242. [CrossRef]

22. Pandey, P.; Tiwary, C.S.; Chattapadhyay, K. Effects of minute addition of Ni on microstructure and mechanical properties of Sn-Zn eutectic alloy. J. Electron. Mater. 2016, 45, 5468-5477. [CrossRef]

23. Gancarz, T.; Bobrowski, P.; Pawlak, S.; Schell, N.; Chulist, R.; Janik, K. Wetting of Sn-Zn-Ga and Sn-Zn-Na Alloys on Al and Ni substrate. J. Electron. Mater. 2018, 47, 49-60. [CrossRef]

24. Lee, J.-E.; Kim, K.-S.; Inoue, M.; Jiang, J.; Suganuma, K. Effects of Ag and Cu addition on microstructural properties and oxidation resistance of Sn-Zn eutectic alloy. J. Alloys Compd. 2008, 454, 310-320. [CrossRef]

25. Liu, J.-C.; Zhang, G.; Ma, J.-S.; Suganuma, K. Ti addition to enhance corrosion resistance of Sn-Zn solder alloy by tailoring microstructure. J. Alloys Compd. 2015, 644, 113-118. [CrossRef]

26. Hu, J.; Luo, T.; Hu, A.; Li, M.; Mao, D. Electrochemical corrosion behaviors of Sn-9Zn-3Bi-xCr solder in $3.5 \% \mathrm{NaCl}$ solution. J. Electron. Mater. 2011, 40, 1556-1562. [CrossRef]

27. Zhang, L.; Han, J.-G.; Guo, Y.-H.; He, C.-W. Properties of SnZn lead free solders bearing rare earth Y. Sci. Technol. Weld. Join. 2012, 17, 424-428. [CrossRef]

28. Tang, C.; Hu, B.; Du, Y.; Zhao, D.; Zhou, P.; Zheng, F.; Gao, Q.; Wang, J. Thermodynamic modeling of the Hf-Sn and Sn-Y systems. Calphad 2012, 39, 91-96. [CrossRef]

29. Li, B.; Shi, Y.W.; Lei, Y.P.; Guo, F.; Xia, Z.D.; Zong, B. Effect of rare earth element addition on the microstructure of Sn-Ag-Cu solder joint. J. Electron. Mater. 2005, 34, 217-224. [CrossRef]

30. Wu, C.M.L.; Wong, Y.W. Rare-earth additions to lead-free electronic solders. J. Mater. Sci. Mater. Electron. 2007, 18, 77-91. [CrossRef]

31. Pourbaix, M.; Franklin, J.A. Potential-pH diagrams. (Book reviews: Atlas of electrochemical equilibria in aqueous solutions). Science 1966, 154, 1537.

32. Latimer, W.M. Oxidation Potentials. Second Edition. Soil Sci. 1952, 74, 333. [CrossRef] 
33. Hao, H.; Tian, J.; Shi, Y.W.; Lei, Y.P.; Xia, Z.D. Properties of Sn3.8Ag0.7Cu solder alloy with trace rare earth element Y additions. J. Electron. Mater. 2007, 36, 766-774. [CrossRef]

34. Abayarathna, D.; Hale, E.; O'Keefe, T.; Wang, Y.-M.; Radovic, D. Effects of sample orientation on the corrosion of zinc in ammonium sulfate and sodium hydroxide solutions. Corros. Sci. 1991, 32, 755-768. [CrossRef]

35. Ralston, K.D.; Birbilis, N.; Davies, C.H.J. Revealing the relationship between grain size and corrosion rate of metals. Scr. Mater. 2010, 63, 1201-1204. [CrossRef]

36. Osório, W.R.; Garcia, L.R.; Peixoto, L.C.; Garcia, A. Electrochemical behavior of a lead-free SnAg solder alloy affected by the microstructure array. Mater. Des. 2011, 32, 4763-4772. [CrossRef] 